\title{
State of the art in the treatment of gastric cancer: from the 71st Japanese Gastric Cancer Congress
}

\author{
Masashi FujiI ${ }^{1}$, Juei SASAKI ${ }^{2}$, and Toshifusa NAKaJima ${ }^{3}$ \\ ${ }^{1}$ Third Department of Surgery, Nihon University School of Medicine, 30-1 Oyaguchikamimachi, Itabashi-ku, Tokyo 173-8610, Japan \\ ${ }^{2}$ Division of Surgery, Niigata Cancer Center Hospital, Niigata, Japan \\ ${ }^{3}$ Department of Gastrointestinal Surgery, Cancer Institute Hospital, Tokyo, Japan
}

\begin{abstract}
:
The recent literatures has few reports of the state of the art and latest results in the treatment of gastric cancer, although such information is necessary for conducting new clinical trials and for obtaining informed consent from patients. In the panel discussions at the 71st Gastric Cancer Congress of Japan (held in Tokyo, June 1999), 18 representative institutions and hospitals in Japan reported their latest results for the surgical treatment of gastric cancer, indicating the state of the art in the treatment of gastric cancer. Here we report a summary of these sessions.
\end{abstract}

Key words: gastric cancer, treatment result, 5-year survival rates

\section{Introduction}

Results of treatment for gastric cancer are reported in a nationwide registry system in Japan [1]. However, in recent years, there have been few reports of the up-todate results from each institution or hospital [2]. Panel discussion sessions at the 71st Japanese Gastric Cancer Congress (held in Tokyo, June 1999) focused on the latest results for the surgical treatment of gastric cancer at 18 representative Japanese institutions and hospitals. The results of gastric cancer treatment in Japan have improved markedly, as a result of early detection and extensive radical surgery. The proportion of patients with early gastric cancer has increased steadily, from approximately $20 \%$ in the 1970 s to $50 \%$ in the 1990 s [1]. Endoscopic mucosal resection (EMR) and limited surgery are commonly employed for patients with early gastric cancer [3], while, D2 or more extensive lymph node dissection has commonly been employed safely

Offprint requests to: M. Fujii

Received for publication on Sept. 6, 1999 for patients with locally advanced gastric cancer [4,5]. At the 71st Japanese Gastric Cancer Congress, "the state of the art" of the treatment of gastric cancer in Japan was discussed, and the results for gastric cancer patents treated surgically in the period 1985 to 1994 at the 18 hospitals and institutions were reported and discussed from various points of view.

\section{Patients and methods}

\section{Participating hospitals and institutions}

The abstracts from 18 cancer institutions and university hospitals were selected from abstracts presented at the 71st Japanese Gastric Cancer Congress. The names of the participating institutions and hospitals and of the authors and co-workers are listed in the appendix.

\section{Patients}

Patients who were treated surgically at the 18 hospitals and institutions from January 1985 to December 1994 were the subjects of the analysis. Patients who were not treated surgically, such as those who were inoperable, or patients treated with EMR, were excluded from this study.

\section{Methods}

The stage classification, depth of tumor invasion, lymph node grouping, and curability of gastric resection were reported according to the criteria in the first English edition of the Japanese classification of gastric carcinoma of the Japanese Research Society for Gastric Cancer [6] and the general rules for gastric cancer study of the Japanese Research Society for Gastric Cancer (12th Japanese edition) [7]. The stage grouping of the first English edition is shown in Table 1. For comparing 
Appendix. Participating institutions and hospitals and authors of abstracts and co-workers

Department of Surgery, Keio University School of Medicine, Tokyo

Kubota T, Wada N, Ishikawa Y, Yokoyama T, Abe S, Kimata M, Egawa T, Tokuyama J, Otani Y, Kumai K, Kitajima M

Third Department of Surgery, Nihon University School of Medicine, Tokyo

Eguchi T, Mochizuki F, Kasakura Y, Fujii M, Iwai S

Institute of Gastroenterology, Tokyo Women's Medical College, Tokyo

Oguma H, Kitamura Y, Takahashi K

First Department of Surgery, Tokyo Medical and Dental University, Tokyo

Honda T, Saeki I, Hayashi M, Tani M, Saito N, Takeshita K, Iwai T

Second Department of Surgery, Kanazawa University, Kanazawa

Fushida S, Bandou E, Miyashita T, Taniguchi K. Kinami S, Nishimura G, Fujimura T, Yonemura Y, Miwa K

First Department of Surgery, Kyoto Prefectural University of Medicine, Kyoto

Hagiwara A, Okamoto K, Shirasu M, Sakakura C, Otsuji E, Kitamura K, Taniguchi H, Sawai S, Yamaguchi T, Yamagishi H, Takahashi T

Department of General and Gastroenterological Surgery, Osaka Medical College, Osaka

Niki M, Okajima K, Nomura E, Fujii K, Nakamura M, Nishiguchi K, Okuzawa M, Ota M, Tanigawa M

Department of Surgery First, Tottori University School of Medicine, Tottori

Ikeguchi M, Oka S, Saito H, Kondo A, Tsujitani S, Maeta M, Kaibara N

First Department of Surgery, School of Medicine, Kagoshima University, Kagoshima

Hokita S, Natsugoe S, Aikou T

Department of Surgery, Cancer Research Institute, Kanazawa University, Kanazawa

Omote K, Minamoto T, Hirano K, Mizoguchi M, Fujimoto T, Takahashi Y, Mai M

Department of Surgery, National Shikoku Cancer Center Hospital, Matsuyama

Kurita A, Kubo Y, Tanada M, Takiyama W, Takashima S, Hosokawa Y, Doi T

Department of Surgical Oncology, Osaka Medical Center for Cancer and Cardiovascular Disease, Osaka

Furukawa H, Hiratsuka M, Nakayama I, Yamada T, Yasuda T, Murata K, Ohigashi H, Kameyama M, Sasaki Y, Kabuto T,

Ishikawa $\mathrm{O}$, Imaoka S

Department of Gastroenterological Surgery, Aichi Cancer Center Hospital, Nagoya

Yamamura Y, Kodera Y, Shimizu Y, Torii A, Hirai T, Yasui K, Morimoto T, Kato T, Kito T

Division of Surgery, Niigata Cancer Center Hospital, Niigata

Nashimoto A, Yabusaki H, Tsuchiya Y, Tanaka O, Sasaki J

Third Department of Surgery, Kanagawa Cancer Center, Yokohama

Sairenji M, Saito M, Yoshikawa T, Tsuburaya A, Kobayashi O, Motohashi H

Department of Surgery, Tokyo Metropolitan Komagome Hospital, Tokyo

Arai K, Iwasaki Y, Ohashi M, Takahashi T

Department of Surgical Oncology, National Cancer Center Hospital, Tokyo

Katai H, Sano T, Sasako M, Fukagawa T, Maruyama K

Department of Gastrointestinal Surgery, Cancer Institute Hospital, Tokyo

Ota K, Ohyama S, Takahashi T, Nakajima T

the treatment results at each institution, the 5-year survival rates, determined by the Kaplan-Meier method, were employed.

\section{Results}

\section{Total number of gastric cancer patients} treated surgically

Gastric cancer has been a leading cause of death in Japan, but since 1993, lung cancer in males has become the number one cause of mortality. The incidence of gastric cancer has been declining dramatically in Western countries [8]. The total number of gastric cancer patients treated surgically in each institution and hospital in the period 1985 to 1994 are listed in Table 2. None of the hospitals or institutions showed a decline in the number of gastric cancer patients treated surgically in this period. Dr. Furukawa, of the Osaka Medical Center for Cancer and Cardiovascular Disease, introduced a report from the Osaka cancer population-based registry showing a declining trend in reported gastric cancer mortality, but indicating that the morbidity of gastric cancer is still the highest among other cancers [9]. Nevertheless, in recent years, since the development of EMR, surgical resections for early gastric cancer are declining [3]. It should be noted that EMR patients will be included in the results for treatment of gastric cancer in future statistics. 
Table 1. Stage grouping in the first English edition of the Japanese classification of gastric carcinoma [6]

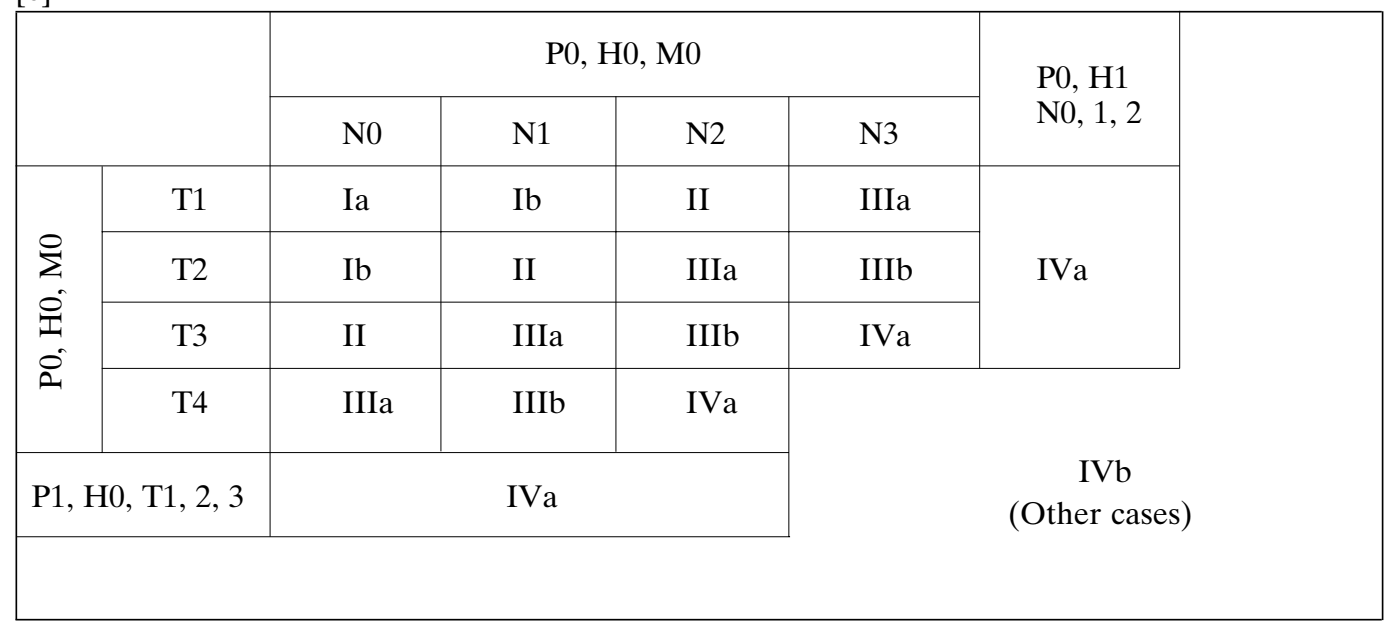

Table 2. Total number of surgically treated gastric cancer patients, and resectability

\begin{tabular}{lccc}
$\begin{array}{l}\text { Institution or } \\
\text { hospital }\end{array}$ & $\begin{array}{c}\text { Number of } \\
\text { patients }\end{array}$ & $\begin{array}{c}\text { Resection } \\
\text { rate }\end{array}$ & $\begin{array}{c}\text { Curative } \\
\text { resection rate }\end{array}$ \\
\hline A & 378 & $94.2 \%$ & $85.7 \%$ \\
B & 790 & $94.9 \%$ & $87.2 \%$ \\
C & 1256 & $92.6 \%$ & $62.8 \%$ \\
D & 1280 & $95.0 \%$ & $80.1 \%$ \\
E & 691 & $97.4 \%$ & $85.2 \%$ \\
F & 886 & $99.3 \%$ & $87.2 \%$ \\
G & 2379 & $96.1 \%$ & $84.7 \%$ \\
H & 1344 & $89.6 \%$ & $85.7 \%$ \\
I & 1211 & $93.3 \%$ & $68.0 \%$ \\
J & 711 & $91.0 \%$ & $83.0 \%$ \\
K & 1207 & $96.4 \%$ & $87.7 \%$ \\
L & 1478 & $98.3 \%$ & $93.7 \%$ \\
M & 1970 & $95.6 \%$ & $89.6 \%$ \\
N & 2343 & $96.7 \%$ & $90.1 \%$ \\
O & 1509 & $96.0 \%$ & $86.1 \%$ \\
P & 1763 & $97.8 \%$ & $82.4 \%$ \\
Q & 2578 & $95.9 \%$ & $89.0 \%$ \\
R & 2597 & $98.9 \%$ & $91.1 \%$ \\
\hline
\end{tabular}

\section{Resectability}

The overall resection and curative resection rates at each hospital and institution are listed in Table 2. The rate of resection reached approximately $95 \%$ at each hospital, ranging from $89.6 \%$ to $99.3 \%$. This highresection rate is based mainly on advances in the diagnosis of early-stage disease. Curative resection rates ranged from $62.8 \%$ to $93.7 \%$, varying according to patient characteristics, such as the frequency of early-stage cancer, or the surgeon's attitude to advanced disease. Dr. Eguchi, of Nihon University, reported that, in their department of surgery, they treated patients with far-
Table 3. Frequency of early gastric cancer

\begin{tabular}{lrrc}
\hline $\begin{array}{l}\text { Institution } \\
\text { or hospital }\end{array}$ & Early & Advanced & $\begin{array}{c}\text { Frequency of } \\
\text { early gastric cancer }\end{array}$ \\
\hline A & 135 & 221 & $37.9 \%$ \\
B & 382 & 408 & $48.4 \%$ \\
C & 562 & 694 & $44.7 \%$ \\
D & 549 & 650 & $45.8 \%$ \\
E & 343 & 348 & $49.6 \%$ \\
F & 454 & 432 & $51.2 \%$ \\
G & 1018 & 1361 & $42.8 \%$ \\
H & 539 & 651 & $45.3 \%$ \\
I & 516 & 568 & $47.6 \%$ \\
J & 331 & 380 & $46.6 \%$ \\
K & 542 & 655 & $45.3 \%$ \\
L & 881 & 597 & $59.6 \%$ \\
M & 1000 & 970 & $50.8 \%$ \\
N & 1175 & 1091 & $51.9 \%$ \\
O & 701 & 808 & $46.5 \%$ \\
P & 759 & 966 & $44.0 \%$ \\
Q & 1273 & 1305 & $49.4 \%$ \\
R & 1294 & 1219 & $51.5 \%$ \\
\hline
\end{tabular}

advanced gastric cancer with neoadjuvant chemotherapy to improve the curative resection rate.

\section{Incidence of early gastric cancer}

Double-contrast radiography and the development of fiberscopes have played a leading role in the detection of increasing numbers of early gastric cancers in Japan. The incidence of early gastric cancer at the 18 hospitals and institutions ranged from $37.9 \%$ to $59.6 \%$ (Table 3 ). In the Japanese nationwide registry, the reported frequency of early gastric cancer was $11.8 \%$ in $1965,26.2 \%$ in 1975, and 48.4\% in 1990 [1]. Dr. Yabusaki and Dr. 
Nashimoto, of the Niigata Cancer Center Hospital, reported the details of their increasing incidence of early gastric cancer. Five of the 18 hospitals and institutions reported rates of early gastric cancer exceeding $50 \%$. The rate of $50 \%$ seems to be a maximum plateau of early gastric cancer detected by conventional diagnostic modalities, but with further investigations using biological techniques, a higher rate of detection of early gastric cancer may be expected.

\section{Surgical complications}

The incidence of surgical complications showed a wide range; $5.1 \%$ to $30.3 \%$ (Table 4 ). Surgical complications included leakage, bleeding, and stenosis, in addition to general complications such as pulmonary, cardiac, and renal complications. Dr. Honda, of Tokyo Medical and Dental University, reported the details of their surgical and general complications in the past 10 years. He reported that there was no evidence of increasing complications in conjunction with the increase in extensive lymphadenectomy. Dr. Arai, of Tokyo Metropolitan Komagome Hospital, reported on their continuous efforts to prevent pancreatic fistula formation after extensive lymphadenectomy.

\section{Direct mortality}

Direct mortality (i.e., operative death), defined as death within 30 postoperative days, occurred in $0.4 \%$ to $2.9 \%$ of the surgically treated patients (Table 4). Reduction

Table 4. Incidence of surgical complications and direct mortality

\begin{tabular}{lcc}
\hline $\begin{array}{l}\text { Institution or } \\
\text { hospital }\end{array}$ & $\begin{array}{c}\text { Rate of surgical } \\
\text { complications }\end{array}$ & Direct mortality \\
\hline A & $20.1 \%$ & $2.7 \%$ \\
B & $10.5 \%$ & $2.4 \%$ \\
C & $18.6 \%$ & $2.9 \%$ \\
D & ND & $1.5 \%$ \\
E & ND & $2.6 \%$ \\
F & $22.1 \%$ & $0.6 \%$ \\
G & ND & $0.8 \%$ \\
H & $15.6 \%$ & $1.9 \%$ \\
I & $5.1 \%$ & $0.7 \%$ \\
J & $28.0 \%$ & $1.0 \%$ \\
K & $6.9 \%$ & $0.6 \%$ \\
L & $15.7 \%$ & $0.9 \%$ \\
M & $9.0 \%$ & $0.5 \%$ \\
N & $10.7 \%$ & $0.7 \%$ \\
O & ND & $1.9 \%$ \\
P & $11.5 \%$ & $0.9 \%$ \\
Q & $30.3 \%$ & $0.4 \%$ \\
R & $26.5 \%$ & $0.9 \%$ \\
\hline
\end{tabular}

See text for explanation of "direct mortality" ND, Not described of direct mortality to less than $0.5 \%$ was proposed as the goal for the next decade.

\section{Five-year survival results}

Five-year survival rates are listed according to depth of tumor invasion (Table 5), lymph node metastasis (Table 6), stage classification (Table 7), and curability of gastric resection (Table 8). Follow-up was completed in $97 \%$ to $100 \%$ of the patients in all hospitals and institutions.

\section{Depth of tumor invasion and lymph node metastasis} (Tables 5, 6)

Five-year survival rates according to depth of tumor invasion ranged from $84.6 \%$ to $97.0 \%$ in $\mathrm{T} 1$ patients, from $46.4 \%$ to $78.9 \%$ in $\mathrm{T} 2$, from $17.0 \%$ to $47.2 \%$ in $\mathrm{T} 3$, and from $0.0 \%$ to $25.7 \%$ in T4. Five-year survival rates according to lymph node metastasis ranged from $76.8 \%$ to $93.3 \%$ in $\mathrm{n} 0$ patients, from $42.4 \%$ to $68.9 \%$ in $\mathrm{n} 1$, from $11.8 \%$ to $47.0 \%$ in $\mathrm{n} 2$, from $0.0 \%$ to $35.0 \%$ in $\mathrm{n} 3$, and from $0.0 \%$ to $11.8 \%$ in $n 4$. Dr. Ikeguchi, of Tottori University, reported the details of survival rates by depth of tumor invasion, and Dr. Hagiwara, of Kyoto Prefectural University, reported survival rates according to lymph node metastasis. These survival rates by depth of tumor invasion and lymph node metastasis seemed to justify the propriety of the Japanese stage classification. However, we note that there were institutional differences in survival rates of $\mathrm{T} 2$ or more and

Table 5. Five-year survival rates according to depth of tumor invasion

\begin{tabular}{lcccr}
\hline Institution or hospital & $\mathrm{T} 1$ & $\mathrm{~T} 2$ & $\mathrm{~T} 3$ & $\mathrm{~T} 4$ \\
\hline $\mathrm{A}$ & $84.6 \%$ & $46.4 \%$ & $18.1 \%$ & $25.7 \%$ \\
$\mathrm{~B}$ & $89.1 \%$ & $75.4 \%$ & $32.0 \%$ & $15.2 \%$ \\
$\mathrm{C}$ & $89.9 \%$ & $72.8 \%$ & $33.7 \%$ & $15.9 \%$ \\
$\mathrm{D}$ & $94.5 \%$ & $59.3 \%$ & $22.8 \%$ & $6.6 \%$ \\
$\mathrm{E}$ & $88.0 \%$ & $50.0 \%$ & $21.0 \%$ & $4.0 \%$ \\
$\mathrm{~F}$ & $88.3 \%$ & $70.2 \%$ & $33.1 \%$ & $8.9 \%$ \\
$\mathrm{G}$ & $94.8 \%$ & $72.6 \%$ & $36.4 \%$ & $10.3 \%$ \\
$\mathrm{H}$ & $92.7 \%$ & $72.2 \%$ & $39.6 \%$ & $11.3 \%$ \\
$\mathrm{I}$ & $89.2 \%$ & $61.1 \%$ & $23.8 \%$ & $22.0 \%$ \\
$\mathrm{~J}$ & $97.0 \%$ & $55.0 \%$ & $17.0 \%$ & $0.0 \%$ \\
$\mathrm{~K}$ & $89.7 \%$ & $76.9 \%$ & $47.2 \%$ & $14.3 \%$ \\
$\mathrm{~L}$ & $91.6 \%$ & $73.9 \%$ & $35.4 \%$ & $15.8 \%$ \\
$\mathrm{M}$ & $93.2 \%$ & $64.5 \%$ & $28.9 \%$ & $13.5 \%$ \\
$\mathrm{~N}$ & $91.3 \%$ & $78.9 \%$ & $42.3 \%$ & $15.8 \%$ \\
$\mathrm{O}$ & $92.2 \%$ & $70.4 \%$ & $32.2 \%$ & $8.6 \%$ \\
$\mathrm{P}$ & $91.8 \%$ & $68.1 \%$ & $26.1 \%$ & $9.6 \%$ \\
$\mathrm{Q}$ & $91.2 \%$ & $75.8 \%$ & $34.9 \%$ & $11.0 \%$ \\
$\mathrm{R}$ & $93.9 \%$ & $71.8 \%$ & $33.6 \%$ & $9.7 \%$ \\
\hline
\end{tabular}

T1, Tumor invasion of mucosa (M) or submucosa (SM); T2, tumor invasion of muscularis propria (MP) or subserosa (SS); T3, tumor penetration of serosa (SE); T4, tumor invasion of adjacent structures (SI) 
n3-4 patients, whereas there were few institutional differences in survival rates of $\mathrm{T} 1$ and $\mathrm{n} 0-2$ patients.

\section{Stage classification (Table 7)}

Good correlation was found between stage classification and the 5-year survival rates in almost all the hospi-

Table 6. Five-year survival rates according to lymph node metastasis

\begin{tabular}{lcccrr}
\hline $\begin{array}{l}\text { Institution or } \\
\text { hospital }\end{array}$ & & & & & \\
\hline $\mathrm{A}$ & $\mathrm{n} 0$ & $\mathrm{n} 1$ & $\mathrm{n} 2$ & $\mathrm{n} 3$ & $\mathrm{n} 4$ \\
$\mathrm{~B}$ & $76.8 \%$ & $42.4 \%$ & $11.8 \%$ & $0.0 \%$ & $11.8 \%$ \\
$\mathrm{C}$ & $85.4 \%$ & $54.7 \%$ & $24.4 \%$ & $2.8 \%$ & $0.0 \%$ \\
$\mathrm{D}$ & $89.0 \%$ & $61.4 \%$ & $42.5 \%$ & $23.5 \%$ & $8.2 \%$ \\
$\mathrm{E}$ & $85.8 \%$ & $41.0 \%$ & $31.0 \%$ & $19.0 \%$ & $8.5 \%$ \\
$\mathrm{~F}$ & $85.0 \%$ & $63.0 \%$ & $47.0 \%$ & $35.0 \%$ & $6.0 \%$ \\
$\mathrm{G}$ & $86.6 \%$ & $68.9 \%$ & $29.9 \%$ & $12.0 \%$ & $3.0 \%$ \\
$\mathrm{H}$ & $90.2 \%$ & $55.0 \%$ & $35.5 \%$ & $11.9 \%$ & $5.7 \%$ \\
$\mathrm{I}$ & $89.5 \%$ & $49.1 \%$ & $32.8 \%$ & $20.8 \%$ & $0.0 \%$ \\
$\mathrm{~J}$ & $87.3 \%$ & $48.5 \%$ & $31.7 \%$ & $24.6 \%$ & $3.6 \%$ \\
$\mathrm{~K}$ & $91.0 \%$ & $65.0 \%$ & $32.0 \%$ & $0.0 \%$ & $5.0 \%$ \\
$\mathrm{~L}$ & $87.4 \%$ & $60.5 \%$ & $39.7 \%$ & $27.5 \%$ & $10.5 \%$ \\
$\mathrm{M}$ & $88.3 \%$ & $64.5 \%$ & $36.0 \%$ & $29.6 \%$ & $4.6 \%$ \\
$\mathrm{~N}$ & $89.2 \%$ & $61.9 \%$ & $34.3 \%$ & $21.6 \%$ & $4.1 \%$ \\
$\mathrm{O}$ & $88.4 \%$ & $63.1 \%$ & $30.5 \%$ & $21.8 \%$ & $9.7 \%$ \\
$\mathrm{P}$ & $88.8 \%$ & $55.8 \%$ & $30.7 \%$ & $6.2 \%$ & $4.4 \%$ \\
$\mathrm{Q}$ & $89.6 \%$ & $59.8 \%$ & $35.7 \%$ & $11.6 \%$ & $6.7 \%$ \\
$\mathrm{R}$ & $89.5 \%$ & $67.2 \%$ & $36.4 \%$ & $9.9 \%$ & $5.8 \%$ \\
\hline
\end{tabular}

n0, No evidence of lymph node metastasis; $\mathrm{n} 1$, metastasis to group 1 lymph nodes, but no metastasis to group 2, 3, and 4 lymph nodes; $\mathrm{n} 2$, metastasis to group 2 lymph nodes, but no metastasis to group 3 and 4 lymph nodes; n3, metastasis to group 3 lymph nodes, but no metastasis to group 4 lymph nodes; $\mathrm{n} 4$, metastasis to group 4 lymph nodes tals and institutions. Dr. Niki, of Osaka Medical College, reported the details of survival rates according to stage classification. In a few hospitals, late survival rates were not correlated with the clinical stage, mainly because of the small number of treated patients. Dr. Sairenji, of Kanagawa Cancer Center, suggested that there was progress in treatment results when the 5-year survival rates were compared between the early and late periods (i.e., 1985-89 vs 1990-94). Dr. Nashimoto, of

Table 8. Five-year survival rates according to curability of gastric resection

\begin{tabular}{lrrr}
$\begin{array}{l}\text { Institution or } \\
\text { hospital }\end{array}$ & Curability A & Curability B & Curability C \\
\hline A & $76.5 \%$ & $33.4 \%$ & $0.0 \%$ \\
B & $88.2 \%$ & $49.9 \%$ & $3.1 \%$ \\
C & $89.0 \%$ & $49.9 \%$ & $5.4 \%$ \\
D & $82.0 \%$ & $37.0 \%$ & $9.9 \%$ \\
E & $85.0 \%$ & $30.0 \%$ & $5.2 \%$ \\
F & $87.1 \%$ & $45.6 \%$ & $13.9 \%$ \\
G & $97.0 \%$ & $57.6 \%$ & $5.9 \%$ \\
H & $91.2 \%$ & $53.3 \%$ & $11.5 \%$ \\
I & $85.7 \%$ & $54.7 \%$ & $5.7 \%$ \\
J & $94.0 \%$ & $46.0 \%$ & $6.0 \%$ \\
K & $89.4 \%$ & $57.2 \%$ & $3.0 \%$ \\
L & $89.6 \%$ & $42.3 \%$ & $1.1 \%$ \\
M & $91.6 \%$ & $43.8 \%$ & $3.1 \%$ \\
N & $89.8 \%$ & $50.0 \%$ & $1.3 \%$ \\
O & $90.0 \%$ & $49.7 \%$ & $6.1 \%$ \\
P & $90.1 \%$ & $45.0 \%$ & $5.7 \%$ \\
Q & $91.3 \%$ & $48.7 \%$ & $7.0 \%$ \\
R & $92.3 \%$ & $43.8 \%$ & $0.0 \%$ \\
\hline
\end{tabular}

Curability A, No residual tumor, with high probability of cure; curability B, no residual tumor, but not evaluable as "curability A"; curability $\mathrm{C}$, definite residual tumor

Table 7. Five-year survival rates according to stage classification (first English edition of the Japanese classification of gastric carcinoma [6])

\begin{tabular}{lccccccc}
$\begin{array}{l}\text { Institution or } \\
\text { hospital }\end{array}$ & Ia & Ib & II & IIIa & IIIb & IVa & IVb \\
\hline A & $87.5 \%$ & $65.6 \%$ & $47.8 \%$ & $31.9 \%$ & $7.8 \%$ & $17.1 \%$ & $5.5 \%$ \\
B & $88.6 \%$ & $87.5 \%$ & $73.2 \%$ & $51.4 \%$ & $31.8 \%$ & $11.1 \%$ & $0.8 \%$ \\
C & $91.5 \%$ & $85.5 \%$ & $74.9 \%$ & $53.6 \%$ & $42.4 \%$ & $14.3 \%$ & $4.5 \%$ \\
D & $92.8 \%$ & $82.8 \%$ & $49.1 \%$ & $44.3 \%$ & $22.7 \%$ & $21.2 \%$ & $5.4 \%$ \\
E & $90.0 \%$ & $77.0 \%$ & $66.0 \%$ & $43.0 \%$ & $57.0 \%$ & $9.0 \%$ & $4.0 \%$ \\
F & $88.9 \%$ & $81.0 \%$ & $77.6 \%$ & $54.3 \%$ & $25.6 \%$ & $16.3 \%$ & $4.0 \%$ \\
G & $95.6 \%$ & $85.5 \%$ & $69.7 \%$ & $54.1 \%$ & $35.2 \%$ & $21.6 \%$ & $4.4 \%$ \\
H & $93.4 \%$ & $88.7 \%$ & $75.9 \%$ & $61.7 \%$ & $40.4 \%$ & $19.7 \%$ & $4.0 \%$ \\
I & $90.7 \%$ & $84.6 \%$ & $61.3 \%$ & $43.6 \%$ & $28.4 \%$ & $28.6 \%$ & $7.7 \%$ \\
J & $97.0 \%$ & $88.0 \%$ & $71.0 \%$ & $45.0 \%$ & $30.0 \%$ & $6.0 \%$ & $3.0 \%$ \\
K & $90.5 \%$ & $84.8 \%$ & $73.7 \%$ & $61.6 \%$ & $52.5 \%$ & $27.5 \%$ & $5.8 \%$ \\
L & $92.0 \%$ & $84.3 \%$ & $73.8 \%$ & $45.9 \%$ & $20.6 \%$ & $30.6 \%$ & $1.6 \%$ \\
M & $94.7 \%$ & $86.2 \%$ & $65.0 \%$ & $54.1 \%$ & $33.1 \%$ & $22.7 \%$ & $2.7 \%$ \\
N & $92.2 \%$ & $84.4 \%$ & $74.5 \%$ & $63.8 \%$ & $41.1 \%$ & $25.5 \%$ & $6.6 \%$ \\
O & $92.9 \%$ & $86.5 \%$ & $69.0 \%$ & $53.0 \%$ & $25.0 \%$ & $11.7 \%$ & $3.4 \%$ \\
P & $92.0 \%$ & $88.3 \%$ & $75.1 \%$ & $47.4 \%$ & $35.8 \%$ & $19.2 \%$ & $4.3 \%$ \\
Q & $92.3 \%$ & $89.0 \%$ & $70.1 \%$ & $58.4 \%$ & $36.1 \%$ & $26.6 \%$ & $4.4 \%$ \\
R & $95.5 \%$ & $91.1 \%$ & $77.3 \%$ & $58.5 \%$ & $39.3 \%$ & $23.0 \%$ & $5.8 \%$ \\
\hline
\end{tabular}


Niigata Cancer Center, at the poster exhibition, reported changes in survival rates according to stage classification in the early and late periods.

\section{Curability of gastric resection (Table 8)}

Five-year survival rates according to the curability of gastric resection (see Table 8 for definitions of curability A,B,C) ranged from $76.5 \%$ to $97.0 \%$ in patients with curability A, from $30.0 \%$ to $57.6 \%$ in those with curability $\mathrm{B}$, and from $0.0 \%$ to $13.9 \%$ in those with curability C. Good correlation was found between curability of gastric resection and the 5-year survival rates in all hospitals and institutions. Dr. Furukawa, of Osaka Medical Center for Cancer and Cardiovascular Disease, showed the results for 5-year survival by curability of gastric resection, and reported significant differences between the three curabilities. Survival results by lymph node dissection were discussed in relation to the extent of lymph node metastasis. Dr. Omote, of the Cancer Research Institute of Kanazawa University, reported significant differences in survival results according to lymph node dissection. Dr. Arai, of Tokyo Metropolitan Hospital, reported advances in D4 lymph node dissection. The abstracts of this session clearly show that the results for D2-4 dissection (extended dissection) for n0-1 lymph node metastasis are better than those for D0-1 dissection (limited dissection). D2 lymph node dissection for $\mathrm{n} 0-1$ seems to be the standard gastrectomy treatment in Japan [10].

\section{Chemotherapy}

Positive results for a multi-center randomized controlled trial of adjuvant chemotherapy and adjuvant immuno-chemotherapy in the Tokai area were reviewed by Dr. Yamamura, of the Aichi Cancer Center. Dr. Eguchi, of Nihon University, reported that the histopathological effects of preoperative oral 5-fluorouracil in gastric cancer may predict the chemosensitivity for each patient [11]. Dr. Otani and Dr. Kubota, of Keio University, reported the results of a multi-center clinical trial of adjuvant chemotherapy using a chemosensitivity test. Patients were divided into two groups according to the results of the histoculture drug response assay (HDRA). There was a significant difference in survival between chemo-sensitive and -resistant groups [12]. Dr. Fushida, of Kanazawa University, reported the results of successful treatment with aggressive neoadjuvant chemotherapy. Recent experience with combination chemotherapy (such as irinotecan [CPT-11] plus cisplatin [CDDP]) for advanced and recurrent gastric cancer was reported by Dr. Ota, of the Cancer Institute Hospital. The incorporation of new approaches to neoadjuvant chemotherapy and new drugs will open new horizons for daily practice.

\section{$E M R$}

Dr. Katai, of the National Cancer Center Hospital, noted the indications, methods, results, and future aspects of EMR. The use of EMR should be encouraged for the treatment of gastric cancer if the indications are strictly adhered.

\section{Less invasive surgery}

The results for less invasive, limited surgery, such as wedge resection, segmental resection, pyloruspreserving gastrectomy, and laparoscopic gastrectomy, were reported. Dr. Oguma, of Tokyo Women's Medical College, reported the findings at their institution and the results for segmental resection. Dr. Kurita, of the National Shikoku Cancer Center Hospital, reviewed recurrences after limited surgery.

\section{Discussion}

The results of treatment for gastric cancer in Japan have improved markedly as a result of early detection and extensive radical surgery. The nationwide registry of gastric cancer patients was begun in 1963, and 251996 cases were collected in the period from 1963 to 1991 [1]. Accrual data from this registry have been reported every year (Table 9). However, there has been no documentation of up-to-date survival data in each hospital and institution in recent years. The present report should meet the clinical need for the latest "state of the art" treatment of gastric cancer. The finding that early gastric cancer accounts for almost $50 \%$ of resected patients seems to be a triumph of the mass survey system. New treatment modalities were proposed by many hospitals for improving the treatment of advanced disease, although little progress has been achieved in this field. Standards for gastric cancer treatment have to be established, as there were considerable differences in the principles of and indications for treatment for locally advanced cancer among the representative 18 hospitals and institutions. A committee for developing practice guidelines for gastric cancer treatment was organized by the Japanese Gastric Cancer Society in 1998, and is engaged in preparing practice guidelines. These guidelines are expected to provide a baseline standard for the daily practice of gastric cancer treatment. We hope the most recent up-to-date results of gastric cancer treatment will be reported in the next 5 years. We believe that presentations of such treatment results in each hospital and institution will be useful for self-assessment and for obtaining informed consent from patients. We believe that the panel discussion sessions at the 71st Japanese Gastric Cancer Congress summarized here 
Table 9. Nationwide registry results for treatment of gastric cancer in Japan

\begin{tabular}{|c|c|c|c|c|c|c|c|}
\hline Year & 1963-1966 & 1967-1968 & 1969-1973 & 1974-1978 & 1979-1982 & 1983-1986 & $1987-1990$ \\
\hline Collected cases & 8411 & 6984 & 15589 & 28604 & 23327 & 28023 & 25588 \\
\hline Resection rate & $76.31 \%$ & $78.25 \%$ & $83.90 \%$ & $85.06 \%$ & $89.19 \%$ & $92.42 \%$ & $94.19 \%$ \\
\hline Direct mortality & $3.97 \%$ & $3.46 \%$ & $2.29 \%$ & $1.82 \%$ & $1.68 \%$ & $1.31 \%$ & $1.03 \%$ \\
\hline \multicolumn{8}{|c|}{ 5-Year survival rate } \\
\hline Stage I & $94.40 \%$ & $96.43 \%$ & $96.41 \%$ & $96.58 \%$ & $98.51 \%$ & $98.86 \%$ & $99.41 \%$ \\
\hline Stage II & $\mathrm{NE}$ & $66.55 \%$ & $71.80 \%$ & $71.98 \%$ & $77.59 \%$ & $77.50 \%$ & $79.91 \%$ \\
\hline Stage III & $\mathrm{NE}$ & $36.63 \%$ & $43.75 \%$ & $44.82 \%$ & $47.53 \%$ & $47.30 \%$ & $49.53 \%$ \\
\hline Stage IV & $\mathrm{NE}$ & $11.26 \%$ & $13.14 \%$ & $14.72 \%$ & $13.84 \%$ & $13.10 \%$ & $13.01 \%$ \\
\hline
\end{tabular}

Resection rate, Resected patients/surgically treated patients; 5-year survival rate according to stage determined by 11th Japanese edition of the General rules for gastric cancer study. Survival rate was calculated by the actuarial method of Cutler and Ederer and evaluated by the relative survival rate; NE, not evaluated (by 11th edition)

could contribute to future developments in gastric cancer treatment.

\section{Conclusions}

The up-to date 5-year survival rates for gastric cancer patients in 18 representative institutions and hospitals are approximately:

Stage Ia, $90 \%$

Stage Ib, $85 \%$

Stage II, $75 \%$

Stage IIIa, $50 \%$

Stage IIIb, 30\%

Stage IVa, $15 \%$

Stage IVb, 5\%

Treatment results for early gastric cancer have reached a plateau, allowing the incorporation of limited surgery in this field. On the other hand, there is little progress in the treatment of advanced gastric cancer. We believe this to be the most important theme in the next decade. State of the art treatment of gastric cancer should be reported periodically to facilitate the proper evaluation of daily practice.

Acknowledgments The authors would like to thank Professor Takeshi Iwanaga for his appropriate statements at the end of the conference.

\section{References}

1. Japanese Gastric Cancer Association (formerly The Japanese Research Society for Gastric Cancer and Miwa Registry-Institute of Stomach Cancer). The registration report and the report of treatment results of stomach carcinoma in Japan (in Japanese) 1970-1999. vol.1-55.

2. Nakajima T, Ohta K, Ohyama K. Tabular analysis of CIH (Cancer Institute Hospital) database. In: Nakajima T, Yamaguchi T, editors. Multimodality therapy for gastric cancer Tokyo Heidelberg New York Berlin: Springer-Verlag; 1999:196-267.

3. Takeshita K, Tani M, Inoue H, Saeki Y, Hayashi S, Honda T, et al. Endoscopic treatment of early oesophageal and gastric cancer. Gut 1997;40:123-7.

4. Maruyama K, Okabayashi K, Kinoshita T. Progress in gastric cancer surgery in Japan and its limits of radicality. World J Surg 1987;11:418-25.

5. Bonenkamp JJ, Hermans J, Sasako Y, van de Velde CJH. Quality control of lymph node dissection in the Dutch randomized trial of D1 and D2 lymph node dissection for gastric cancer. Gastric Cancer 1998;1:152-9.

6. Japanese Research Society for Gastric Cancer. Japanese classification of gastric carcinoma. 1st English ed. Tokyo: Kanehara; 1995.

7. Japanese Research Society for Gastric Cancer. The general rules for gastric cancer study (in Japanese). 12th ed. Tokyo: Kanehara; 1993.

8. Tominaga S, Kuroishi T, Aoki K, editors. Cancer mortality statistics in 33 countries 1953-1992, UICC. Nagoya: Roppo Shuppan; 1998.

9. Oshima A, Ajiki W, Tanaka H, Tsukuma H. Significance and usefullness of cancer registries. Int J Clin Oncol 1998;3:343-50.

10. Omote K, Minamoto T, Kitakata S, Hirano K, Mizoguchi M, Fujimoto T, et al. Surgical therapy for gastric carcinoma (in Japanese). Proc Jpn Gastric Cancer Congress 1999;71:31-9.

11. Fujii M, Kosaki G, Tsuchiya S, Kimura K, Suzuki H, Nakajima T, et al. Histopathological effect of preoperative chemotherapy using oral 5-fluorouracil in patients with operable gastric cancer. In: Nakajima T, Yamaguchi T, editors. Multimodality therapy for gastric cancer. Tokyo Heidelberg New York Berlin: Springer; 1999:126-30.

12. Kubota T, Otani Y, Kumai K, Kitajima Y. Future clinical trial of adjuvant chemotherapy with sensitivity tests. In: Nakajima $\mathrm{T}$, Yamaguchi $\mathrm{T}$, editors. Multimodality therapy for gastric cancer. Tokyo Heidelberg New York Berlin: Springer; 1999:1639. 